\title{
Fundamentos
}

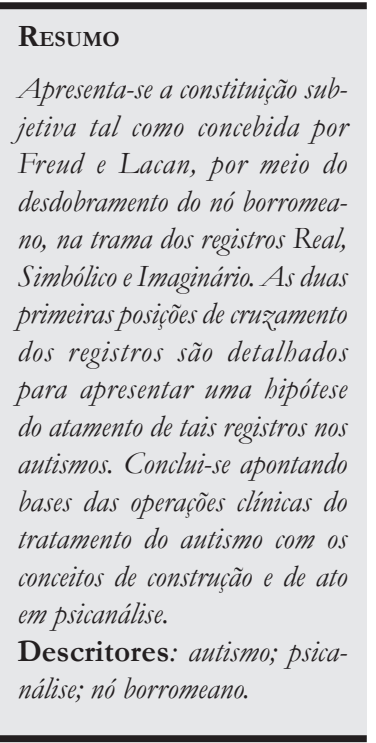

\section{PARADOXOS DO DIAGNÓSTICO PSICANALÍTICO NOS AUTISMOS}

Angela Maria Resende Vorcaro

DOl: http//dx.doi.org/10.11606/issn.1981-1624.v21i3p736-755

Ir randes mudanças da realidade psíquica atravessam a condição infans, exigindo que mantenhamos a tensão entre as hipóteses de uma condição estrutural instituida e o não decidido da estrutura do sujeito. Desconsiderar essa tensão é desencadear a dispersão do que a psicanálise traz de subversão à ideia de uma fixidez do indivíduo, quando considerado como unidade totalizante. Essa consideração do não decidido provoca e sustenta o trabalho clínico com crianças e jovens, mas especialmente nos ditos quadros do espectro autista. Isso porque a demarcação diagnóstica prévia de uma estrutura clínica é capaz de produzir resistência suficiente para impedir a escuta do inconsciente que resvala às classificações que o pré-concebem.

Mesmo que tácita, a ficção teórica construída pelo clínico orienta sua prática e permite expô-la à refutação. Portanto, é necessário, na clínica, suportar e localizar o insabido e a contingência que a teoria necessariamente inclui. Nessa direção, é de extrema relevância debater a concepção teórica que referencia a prática clínica que se expõe aos constrangimentos impostos pelos autistas, esses sujeitos que, aparentemente, estariam fora da linguagem por pouco falarem.

Psicanalista. Professora do Departamento de Psicologia da Universidade Federal de Minas Gerais (UFMG), Belo Horizonte, MG, Brasil. 
Para conceber o que está em jogo na condição do autismo, orientamo-nos pelo Seminário 22 (1974-1975), de Lacan, e pelas formulações de Milner (2006, pp. 7-14). As dimensões Real, Simbólico e Imaginário - também chamadas de "casas do dito" (diz-mansão, Lacan, 2009, p. 25) constitutivas da realidade subjetiva - são distinguidas e consideradas já presentes, ainda que não articuladas, desde o momento em que o neonato vem ao mundo. Nossa hipótese é a de que as diversas modalidades pelas quais o ser incorpora e se defende desses registros define sua condição subjetiva. Pretendemos mostrar como, no caso do autismo, esse enodamento encontrará condições particulares.

\section{A constituição do sujeito a partir do nó borromeano}

Conforme apontado em outras oportunidades (Vorcaro, 1997, 2009), importa localizar o modo borromeano de atar esses registros, apresentado por Lacan (1982, 1973-1974), a partir da consideração de que a barra entre significante e significado é uma reta infinita e da equivalência matemática entre reta infinita e círculo. Assim, três retas infinitas, depois de trançadas em seis cruzamentos, se apresentam como círculos, em que cada um destes sustenta-se nos outros dois. O nó borromeano de três elos permite então mostrar a maneira de operar espaço e tempo habitados pelo sujeito, implicando uma geometria tridimensional cujos pontos se determinam pela cunhagem de três círculos vazados, enganchados e inseparáveis, que destacam a combinatória das relações que presidem a realidade psíquica.

Tudo o que se pode supor como consistência de uma criança não é suficiente para delimitá-la. Entretanto, o suporte do nó borromeano permite discernir suas outras dit-mansões. Para tanto, é necessário situar o alcance da coincidência entre a suposta consistência da criança atribuída por seus cuidadores como dimensão imaginária (I), o efeito indiscernível do que sofre como dimensão real (R) e uma ordem transmissível estabelecida na medida da incidência do simbólico sobre esse organismo (S). Os seis cruzamentos entre RSI serão considerados até seu retorno ao ponto de partida.

Posição 0: Precede o início do trançamento e dá a condição de possibilidade

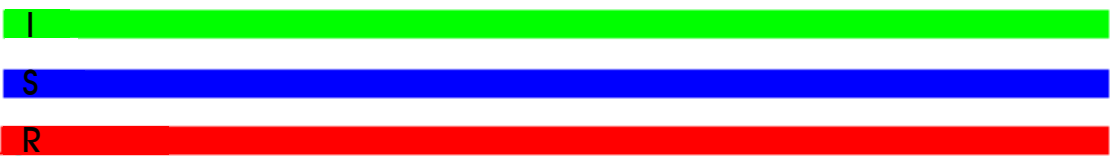


Atribuímos ao Real o que há de indiscernível e irrepresentável no neonato. Tratamos o Simbólico desde a primeira intimação do neonato a habitar a linguagem, discernindo-o do Real. Afetando o organismo por efeito do zumbido da linguagem, antes de elementos da língua serem, por ele, diferenciados, a linguagem posiciona-o em seu campo, cunhando, a partir das vivências do neonato, simples traços sem atributos que fazem o litoral entre Real e Simbólico numa constelação de letras que enquista lalíngua. Sobre essa opacidade o campo Simbólico tecerá sua rede, em sua equivocidade. O Imaginário refere, inicialmente, os sentidos com que o agente materno acolhe o infans ao representá-lo, configurando-o como falo e conferindo-lhe significações. Esse imaginário será assimilado, especularmente, alojando a fantasia.

Os registros R, S e I, planificados como três linhas infinitas vizinhas, se deformarão, na medida em que uma das linhas se sobrepõe à outra.

Posição 1: A fissura Real incide no Simbólico - recalque primário como distinção do corte que opera a privação, pela oposição ser e não ser.

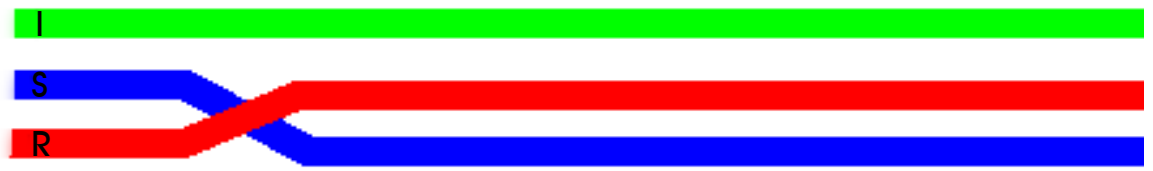

Posição 2: O Imaginário encobre a biância Real no simbólico por meio da frustração. A criança constata biância também no Outro, franqueando o resto (objeto a) que lhes é comum e com o qual estabelecerão trocas.

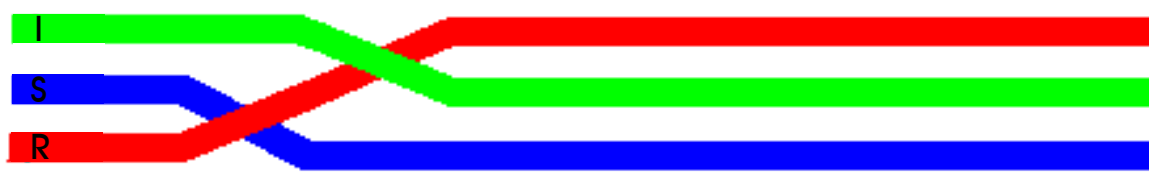

Posição 3: Demarcação simbólica do imaginário - estádio do espelho em que o eu distingue-se como falo $(\varphi)$, recobrindo sua posição como objeto a materno.

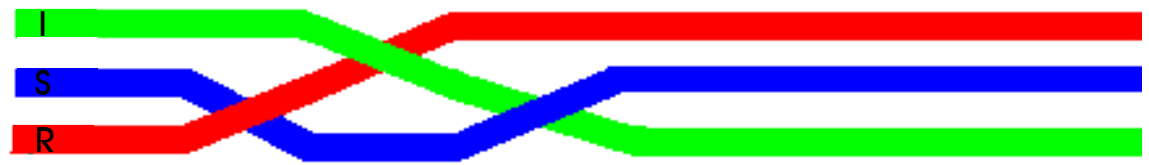


Posição 4: Fissura real da equivalência simbólica ao falo. A função Nome-do-pai emerge como real-é impossivel ser o falo.

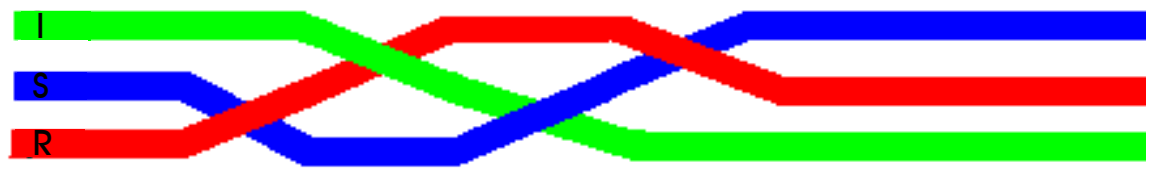

Posição 5: Recobrimento imaginário da interdição real - A função Nome-do-pai é situada imaginariamente pela criança, supondo um agente da interdição.

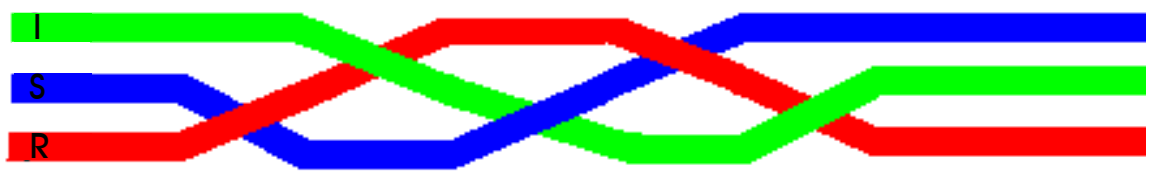

Posição 6: O Simbólico se decanta do Imaginário na metáfora paterna, em que uma unidade de medida pode regular relações entre desejo e lei, conferindo-lhes uma lógica, referida ao Nome-do-pai.

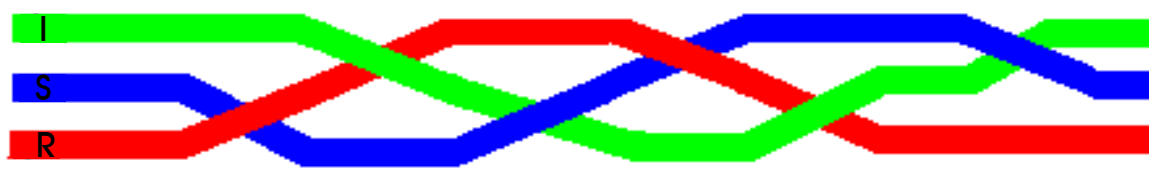

Essa trança ordena a estruturalidade de um sujeito constringido pelas dimensões Real, Simbólica e Imaginária, mas suas superposições se mantêm no constrangimento que os enlaça. O que foi considerado no trançamento como linhas implica a retroação que lhe confere sua condição circular.

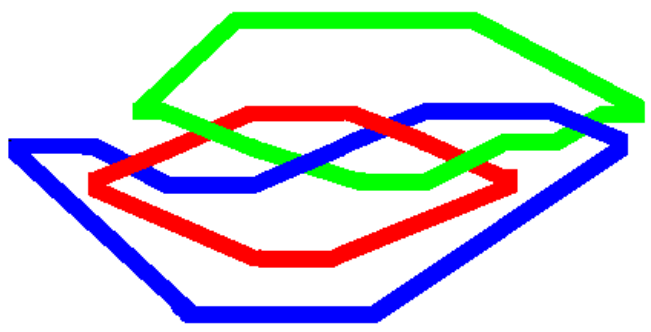

Do investimento fálico da alteridade no infans, traça-se a incidência da ordem significante que se instaura a partir da função imaginária do falo, promotora 
da operação metafórica do Nome-do-pai que evoca o falo como referente. $\mathrm{O}$ sujeito carrega a causa que o divide, inscrevendo-se pela perda que só existe depois da simbolização lhe indicar o lugar. Entre a atribuição fálica e sua significação temos o lapso que a trança percorre. Nessa estrutura temporal reversiva a castração retroage ao recalcamento originário para lhe conferir significância.

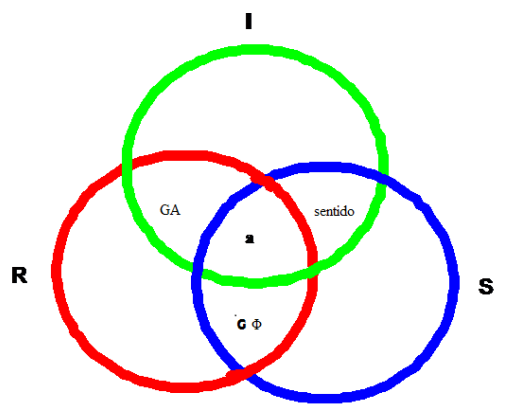

As três dimensões se repetem incessantes e indestrutíveis, fazendo coincidir lei e desejo numa determinação recíproca que, no sintoma e no fantasma, constringe as condições de gozo de um sujeito, ou seja, sua realidade psíquica, orientada pela promessa implicada na versão paterna de gozo ${ }^{1}$.

A tripartição RSI, tracionada pela relação que a sustém, é mediada por esse ponto central, onde se encurralam os cruzamentos de R, S, I. "Tudo que é sujeito, sujeito de pensamento que se imagina ser Ser, é determinado pelo $a$ " (Lacan, 1974-1975). Dos primeiros encontros com o Outro sobram, no corpo, resíduos inapreensíveis, só localizados logicamente. Lacan (2005) os considerou relativos às formas de vazio que se conjugam na delimitação das bordas corporais, encobertos como objetos cedíveis: seio e fezes, mas também olhar e voz. Assim, o objeto a encobre e demarca a causa vazia da realidade psíquica de um sujeito desejante: o objeto que viria satisfazer seu gozo mantém-se irredutivelmente alhures.

\section{Um detalhamento dos dois primeiros tempos da trança borromeana}

A primeira operação da constituição do sujeito reúne o ser ao campo que lhe faz alteridade. Trata-se da operação de alienação

740 Estilos clin., São Paulo, v. 21, n. 3, set./dez. 2016, 736-755. 
(Lacan, 1964/1988c), em que o campo simbólico no qual a criança está mergulhada inicialmente incide em seu organismo sem deixar marcas. Obedecendo ao processo primário, este teria cargas de investimentos livremente móveis, que fluem pressionando a descarga. Assim, as percepções iniciais não conservam nenhum traço (Freud, 1895/1977, p. 317).

Buscando homeostase, o organismo se afeta por diferenças, que o marcam: tensão/apaziguamento; necessidade/satisfação; presença/ausência. Forma-se, então, o primeiro registro das indicações de percepção. Tais diferenças seriam assimiladas pela percepção que cunha seus resíduos por meio da facilitação (permitindo ao fluxo percorrer o mesmo caminho), desde que haja certa intensidade da impressão recebida e insistência de frequência. Entretanto, é impossível impedir que o aparelho seja inundado de estímulos. As "percepçôes que colidem com o aparelho psiquico" (Freud, 1895/1977, p. 317) formam o primeiro registro das percepções dispostas conforme associações de simultaneidade. Resta-lhe, então, tentar lidar com esse excesso de estímulos "capturando-o ou enlaçando-o psiquicamente para poder processá-lo” (Freud, 1920/2006, p. 154). O enlaçamento demarca o fluxo antes livre num estado de repouso, prendendo as cargas de investimento (Freud, 1920/2006, p. 155). Fracassos aí produzem perturbação traumática.

Para Lacan (1988a), os signos de percepção seriam marcas que perderam seu conteúdo para subsistir como um traço apenas indicativo, demarcando acontecimentos que ultrapassaram a homeostase do aparelho. De cada experiência capturada, restaria apenas um traço da diferença em relação à regência do prazer.

O recalque original: uma fissura Real incide no ponto simbólico que localizava o infans no campo discursivo (Simbólico)

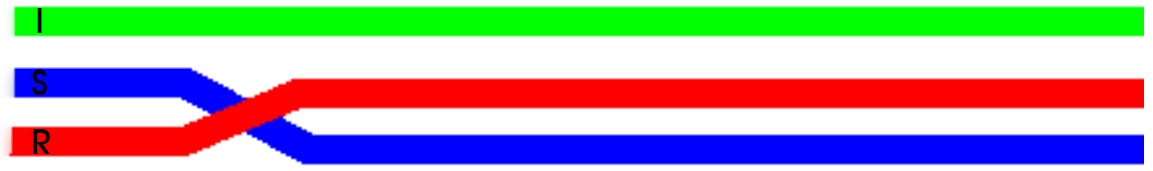

Dentre esses traços vazios de qualquer consistência, alguns serão resublinhados, transformados em função significante, que permitirá as associações com representações-de-palavra. Lacan (1961-1962) retoma a noção freudiana de recalque original (Urverdrängt) como fundadora do inconsciente. Esse recalque original estabelece uma fixação que mantém inalterado o representante e seu enlace à pulsão. Além disso, exerce atração sobre tudo com que estabelece conexão.

Freud (1926/1992, p. 90) supôs o recalque original por considerar que "fatores quantitativos como a intensidade hipertrófica da excitação e a ruptura da proteção contra estímulos constituam as ocasiões imediatas das repressões primordiais". Portanto, haveria no recalque originário uma espécie de saber 
acéfalo que preserva o organismo da força excessiva de excitação, recalque que estaria recalcado desde a origem, rasura de traço algum que seja anterior (Lacan, 2009, p. 113): "O Urverdräng quer dizer que há, na estrutura, uma ligação significante completamente radical: o elemento de impossibilidade como fato de estrutura. Esse impossível é o real, que surge como escolho lógico daquilo que, do simbólico, se enuncia como impossível" (Lacan, 1992b, p. 84).

A linguagem marca o corpo infans sob a forma de corte, inscrevendo o traço vazio de função estruturante, na medida em que divide o ser entre a positividade fálica atribuída a ele e sua negatividade $(-\varphi)$, em que não é nada sem o Outro. A mãe, sujeito da onipotência imaginária, é a imagem invertida da impotência do infans, conceito vazio sem objeto, puro conceito da possibilidade, real negativado de um possível que não é real. "Dizer que o sujeito constitui-se primeiramente como menos um (-1) é dizer que é como Verwerfung que nós o vamos encontrar" (Lacan, 1961-62, inédito). Por isso, a privação concerne ao ponto central da estrutura da identificação do sujeito. As voltas da repetição visam a fazer ressurgir o unário primitivo, coextensivo à estrutura do sujeito.

Freud (1921/2013) localizara a identificação como a forma mais originária de laço. O objeto ansiado e apreciado é incorporado através do comer [Essen] e, assim, é aniquilado. Essa identificação ao pai é, para Freud (1923/2007, p. 42, grifos nossos), o precursor do laço objetal ao pai:

Em um primeiro momento, essa identificação não parece ser a consequência nem o resultado de nenbum investimento objetal, pelo contrário, ela é uma identificação direta e imediata, anterior a qualquer investimento de objeto. No entanto, as escolhas objetais do primeiro período sexual, que se dirigem ao pai e à mãe, parecem desembocar, ao longo do desenvolvimento normal nessas identificações iniciais, reforçando dessa forma, a identificação primária.

A perspectiva lacaniana considera que toda possibilidade de distinguir uma coisa qualquer como também qualquer ausência, lacuna ou intervalo, depende de sua localização simbólica: "A identificação pivô, a identificação-mor, é o traço unário, é o ser marcado pelo um" (Lacan, 1992b, p. 146). Essa identificação demarca e rasura o que havia antes: todo o registro da identificação assenta-se na relação ao significante no Outro, "significante que, no registro da demanda, é caracterizado em seu conjunto como o sinal da presença do Outro" (Lacan, 1998a, p. 355). A forma primária de identificação é com 
insígnias do Outro, e tal identificação permite a fixação do ponto do desejo sob a condição de se identificar a um pequeno traço:

Esse ponto, grande I do traço único, este signo do assentimento do Outro... Basta que o sujeito vá coincidir ali em sua relação com o Outro para que este pequeno signo, este einziger Zug, esteja a sua disposição... A satisfação narcísica... depende da possibilidade de referência a este termo simbólico primordial que pode ser mono-formal, mono-semântico, ein einziger Zug (Lacan, 1992a, p. 344).

Nessa concepção, recalque originário e identificação canibalística ao pai tem o mesmo estofo: na identificação primária tratar-se-ia da identificação a esse traço, ligação primária a que um primeiro representante se atará para sustentar o represamento, evitando o livre escoamento. A partir da identificação a esse traço, inaugura-se a cadeia de ligações subsequentes que, ao substituí-lo, o rasuram, revelando o sujeito (Lacan, 2005).

A perda do gozo do ser é marcada pelo traço que a representa: perda de identidade de percepção, pois o ser é subsituado pelo significante do Outro. Esse traço demarca a perda, e não a consistência da satisfação (Lacan,1961-1962). Trata-se da identificação forçada, sem escolha: identificação ao traço da linguagem que demanda imperativamente que o neonato venha a ser. De início, todos os significantes se equivalem, jogando apenas com a diferença de cada um com todos os outros, mas um pode vir em posição de significante-mestre: "Só que o sujeito que ele representa não é unívoco. Está representado, é claro, mas também não está representado" (Lacan, 1992b, p. 83).

A diferenciação de lalíngua mostra como o sujeito se aliena e se inscreve singularmente na linguagem. Depois de ser afetado pelo que da linguagem ecoa em seu corpo, em-forma-se à linguagem para apropriar-se do campo do saber. Nesse percurso, o sujeito se inventa, praticando um saber que desconhece. Isso porque, enquanto funciona no discurso estabelecido, orienta-se por seu desejo, que desliza por baixo do que diz, evocando o gozo, que insiste nas fissuras da linguagem. Localizar essa emergência no simbólico implica a dificuldade de nomeá-lo. Lacan (2009) a distinguiu com o subterfúgio do semblante lalingua, já que tal irrupção faz equívoco ao objetivar o real. Assim, lalíngua é o precipitado do rastro do sujeito na nuvem de significantes do discurso. Ela reproduz a parte do que subsiste do sujeito alojando o recalcado.

O Um de lalíngua instaura o envolvimento que encadeia os significantes (Lacan, 1982). Neste Um - que não se sabe se é fonema, 
palavra, frase ou mesmo o pensamento - age o gozo anômalo do não sabido, ou seja, saber impossível de se reajuntar, saber de lalíngua. Elucubrando lalíngua o inconsciente estrutura-se como uma linguagem. O inconsciente é feito de lalíngua materna e, por isso, a diferença entre um significante e outro é extraída de lalíngua para constituir o sujeito que coabita ali, pontual e evanescente. Freud (1896/1977, p. 319) já denominara os traços não submetidos à transcrição posterior que os inibiria, como "fueros" sobreviventes.

Para Lacan (1982), o inconsciente é estruturado como os ajuntamentos de coisas heteróclitas de que a teoria dos conjuntos trata como sendo letras. Diferentemente dos matemáticos, para quem as letras designam esses conjuntos, ele insiste em que "as letras são, e não designam, esses ajuntamentos. Elas são tomadas como funcionando como esses ajuntamentos mesmos" (Lacan, 1982, p. 65-66). Assim, o signo - e aí podemos retomar o signo de percepção freudiano não é signo de alguma coisa, mas de um efeito do funcionamento significante: "Esse efeito, é... o sujeito" (p. 68).

Sublinhamos, portanto, que o que se imprime inicialmente é o ferrão do zumbido da linguagem falada no corpo vivo, cortando-o. Antes da estruturação da linguagem no inconsciente, os ajuntamentos de marcas do que ressoa no corpo farão letras. O corte real, efeito de um funcionamento significante, será aludido por precipitados de lalíngua.

O real lacaniano é sedimento de marcas esvaziadas de qualquer predicado, como efeito da linguagem falada ecoando num corpo infans, fazendo letras que carreariam as cadeias significantes que elucubram sobre elas. Trata-se de "algo que a criança viu e ouviu na época em que mal era capaz de linguagem e que agora força seu caminho à consciência, provavelmente desfigurado e deslocado" (Freud, $1937 / 1975$, p. 268). O simbolismo está "ligado a nosso pensamento arcaico, nossa 'língua fundamental”' (Freud, 1925/2011, p. 329). Assim, lalíngua preservada é transmitida encoberta.

A alienação ao discurso decorrerá desse primeiro afeto, na medida em que o gozo do ser sofre os efeitos do Outro que "faz alto ao gozo" (Lacan, 1982, p. 36), conduzindo-o ao funcionamento organizado pelo discurso. Essa alienação se suporta na forma lógica da reunião, que impõe uma escolha entre seus termos ao eliminar um deles, sempre o mesmo, seja qual for a escolha (Lacan, 1964/1998c, p. 885). Entre o ser e o sentido induzido pela função significante, o sujeito subsiste como sentido, sofrendo a perda que o decepa de seu não senso de 
gozo livre. O ser aparece então como sentido, como representação produzida pelo significante unário, $\mathrm{S}_{1}$, e, em seguida, ele aparece como afânise, no significante binário, $\mathrm{S}_{2}$, representante da representação, causa de seu desaparecimento. "Não há sujeito sem, em alguma parte, afânise do sujeito, e é nessa alienação, nessa divisão fundamental, que se institui a dialética do sujeito" (Lacan, 1988b, p. 209). Longe de ser ausência, conotação de um buraco, exprime redução, desaparecimento não acabado (Lacan, 1961-1962).

Trata-se da ausência que pressupõe a presença; rasura que implica uma permanência. Tal como a negação que supõe a afirmação na qual se apoia, afirma alguma coisa do real que não está simplesmente suprimida, mas concerne fundamentalmente o ser na medida em que é eternizada como traço. $\mathrm{O}$ não um confere à casa vazia a notação -1 , ausência que suporta qualquer existência. $\mathrm{O}$ sujeito advém dessa privação primeira a que se articularia a perda primordial do objeto:

Só o sujeito pode ser esse real negativado por um possível que não é real [mas, sim, simbólico]. $\mathrm{O}-1$, constitutivo do ens privativum, nós o vemos assim ligado à estrutura a mais primitiva de nossa experiência do inconsciente, na medida em que ela é aquela, não do interdito, nem do dito que não, mas do não-dito, do ponto onde o sujeito não está mais para dizer se ele não é mais mestre dessa identificação ao 1 , ou dessa ausência repentina do 1, que poderia marcá-lo (Lacan, 1961-1962).

A privação aborda essa exclusão primitiva em que o sujeito constitui-se primeiramente como -1 . O sujeito nasce no lugar do Outro e o significante o revela: "Todo o posicionamento posterior do sujeito repousa na necessidade de uma reconquista desse não-sabido original" (Lacan, 2005, p. 75).

A essa lacuna entre os significantes, Lacan (1988b, p. 26) dá a função da causa. Devido a essa hiância, a causa se distingue da lei determinante da concatenação significante: "entre a causa e o que ela afeta, há sempre claudicação" (p. 27). A pulsação inconsciente mostra a hiância por onde o sujeito se conforma a um real. A falha nessa conformidade, na fenda da causa há algo que é da ordem do não realizado, "algo em espera" onde o recalque derrama alguma coisa: "Mas esse lugar de sujeito original, como haveria este de encontrá-lo na elisão que o constitui como ausência?" (Lacan, 1966/1998d, p. 686).

A operação de alienação ao sentido do Outro, dada pela função da dupla de significantes, implica um resto, localizado por Lacan (1992b, p. 82-83) como a via que reverte a da alienação: "Ali, em determinado ponto de ligação, especialmente aquele absolutamente primeiro, do $\mathrm{S}_{1}$ ao $\mathrm{S}_{2}$, é possível que se abra essa falha, que se chama sujeito". Entretanto, a primeira dupla de significantes pode se solidificar, impedindo a abertura dialética. 


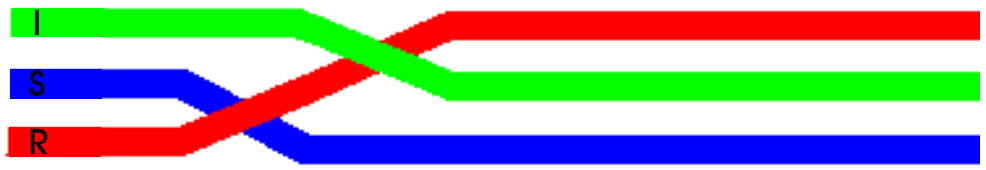

Essa relação entre o significante que representa o sujeito (insígnia) e o significante em posição de representante da representação $\left(\mathrm{S}_{2}\right)$ é ainda insuficiente para que o ser advenha a sua enunciação, pois entre eles é necessário que o sujeito se situe em exterioridade a eles, separado deles. É preciso formular ainda o modo pelo qual o ser responde, como sujeito, a esse prévio funcionamento simbólico.

Enquanto no animal alguns sinais biológicos são cativantes, implicando um comportamento que liga diretamente o portador do sinal com quem o percebe, no ser falante estabelece-se um intervalo entre os sinais acionados e seu autor: os sinais são rastros separados daquele que o emite. Assim, a matriz simbólica mínima já presente permite que a criança situe o agente materno como: 1) agente da privação de seu gozo pleno e 2) agente que traz a possibilidade de satisfação. A criança supõe, nesse agente, um saber pleno sobre seu usufruto da vida (ou seja, seu gozo). Sob a sustentação desse campo simbólico agora articulado, a frustração imaginária recobrirá a falta real pressentida na impossível identidade de percepção.

A articulação exaustiva da entrada em jogo do significante não se reduz a substituir o que não está ali, ao contatar a presença ou a ausência materna: "O que não está ali, o significante não o designa, ele o engendra. O que não está ali, na origem, é o próprio sujeito” (Lacan, 1967-1968). Para afirmar que, de fato, haja sujeito, é necessário que o objeto a se articule. É o que a fórmula ( $\$ \triangleright$ a) impõe: tanto a existência de fato (dos seres falantes) quanto a existência lógica (manejável por significantes).

Inicialmente, a relação de representação entre significantes não constitui o sujeito, apenas acomoda o objeto em que o ser se aliena: o sujeito emergirá então no estado de sujeito barrado, vindo do lugar em que foi inscrito para o lugar em que vai novamente inscrever-se, o objeto preenchendo a função de primeiro referente da falta do sujeito, a que todos os outros significantes se endereçam.

Os círculos de Euler (Lacan, 1988b) localizam, entre o Outro e o sujeito, a interseção do objeto a. O sujeito se institui como uma relação de falta com esse $a$ que é do Outro, querendo se situar

746 Estilos clin., São Paulo, v. 21, n. 3, set./dez. 2016, 736-755. 
no Outro ou amputá-lo do objeto a. Assim, a relação do sujeito com o objeto a comporta as duas operações lógicas: reunião (submissão do ser ao campo do Outro) e interseção (extração que define o objeto a). O objeto a representa uma falta que institui a estrutura do desejo. Seio, fezes, olhar e voz são as peças destacáveis e religadas ao corpo, que sustentam a condição de destacamento e de religação ao objeto a (Lacan, 2008). Para fazer o a é preciso estar prestes-a-fornecê-lo, mas, para fazer a fantasia é preciso o prestes-a-carregá-lo (Lacan, 1969-1970) como peça separável do corpo e profundamente religada ao campo do Outro que o cartografa, o objeto a não é o imaginário que ali se engancha.

Pela operação de separação, o sujeito acha a via de retorno da alienação. Na medida em que o sujeito vem a representar sua partida na separação, o significante binário cai por baixo: "O de que o sujeito tem de se libertar é do efeito afanístico do significante binário" (Lacan, 1988b, p. 208) que, ao ser passado ao inconsciente como significante, será o ponto de atração para os outros recalques.

Naquilo que é significado pela dupla de significantes aparece algo como falta no intervalo que os liga. Trata-se do desejo do Outro. O sujeito se suspende como Isso sob uma forma interrogativa e se articula: "É?", em estado nascente, em presença do Outro que lhe responde (Lacan, 2013). O sujeito acha o ponto fraco do casal primitivo da articulação significante com que o agente do Outro o localiza e acaba com a circularidade de sua relação ao Outro, operando uma torção essencial. O desejo oferecido ao balizamento do sujeito no Outro tem vigência no intervalo entre esses dois significantes: intervalo em que o próprio desejo materno está para além ou para aquém do que ela diz, em que seu desejo lhe é desconhecido. Ao demarcar e separar-se desse ponto de falta o sujeito se constitui.

A separação surge do recobrimento de duas faltas. O sujeito encontra uma falta na intimação que o Outro, por seu discurso, lhe faz. Nos intervalos próprios à estrutura da linguagem desliza algo além do dito, desejo do Outro, apreendido pelo sujeito nas faltas do discurso. Para responder a isso, o sujeito traz a falta antecedente do próprio desaparecimento de seu ser, que ele agora situa no ponto da falta do Outro. A fantasia de seu desaparecimento é o primeiro objeto que o sujeito tem a pôr em jogo nessa dialética; sua própria perda é o primeiro objeto que propõe a esse desejo materno: isso me concerne, mas o que quer? Pode me perder? Uma falta recobre a outra numa dialética que faz a junção do desejo do sujeito com o desejo do Outro, pois a falta engendrada pelo tempo precedente serve para responder à falta suscitada pelo tempo seguinte. Separado de seu lugar prévio - a cadeia significante -, o sujeito deixa de estar ligado ao sentido da 
alienação e localiza seu resto no objeto a: elemento não significante que tampona o intervalo significante (o desejo do Outro), atravessado entre os significantes. Nesse ponto de falta, o sujeito, efeito do significante, articula-se ao elemento não significante que faz interseção entre os significantes. Aí o sujeito representa sua parte e joga sua partida na separação, engendrando-se, pondo-se no funcionamento da linguagem (Lacan, 1988b).

O sujeito não encontra o significante que autentique a cadeia significante. Ele depende do querer do outro: não há garantia. Diante desse impasse, o sujeito faz vir de algures, do registro imaginário, uma parte dele mesmo, engajada na relação imaginária ao outro. Surgindo no lugar da interrogação sobre o que ele é, produz-se o objeto ao redor do qual ele encontra seu suporte (Lacan, 2013). Na medida em que tenta referir-se, o sujeito não se encontra, pois só está nos intervalos, nos cortes. Por isso, recorre ao objeto imaginário no fantasma. Assim, os pedaços do corpo que ele próprio e o Outro rejeitam - e que se intercalam entre os dois - serão erotizados. O objeto, ponto de esteio concreto das margens da consciência, é o suporte imaginário da relação de corte no simbólico que o sujeito tem que suportar. A relação dos objetos reais na relação estreita com as funções vitais do sujeito com a fenda da linguagem é a de recobrimento de dois cortes. $\mathrm{Na}$ superposição de duas faltas, o sujeito encontra na falta do Outro o equivalente ao que ele é como sujeito do significante.

A referência lacaniana para o objeto a também é resgatada do argumento de Winnicott, pelo qual a relação da criança com a mãe "sofre de imediato interferência por essas funções desse miúdo objeto, do qual Winnicott vai nos formular o estatuto" (Lacan, 1967-1968). O objeto transicional está, para Lacan (1967-1968), em relação com o primeiro objeto de gozo, que se localiza, nesse momento, não no seio da mãe (que não é permanente), mas, antes, no polegar da mão da criança (sempre à mão): “ele não está nem no interior, nem no exterior, nem é real, nem ilusório". Remetendo-se ao Freud de "O Ego e o Id" (1923), Lacan (1967-1968) resublinha que o primeiro objeto é o eu-prazer, eu mesmo, que me pertence, é regra do meu prazer. Por isso, à preciosa descrição winnicottiana, só lhe falta constatar que o objeto transicional é o broto, a ponta, a primeira saída da terra do que o objeto a comanda, a saber, o sujeito (Lacan, 1967-1968). Assim, 
um ser capaz de ler seu vestígio, basta isso para que ele possa reinscrevê-lo noutro lugar que não aquele a que o levaria inicialmente. Essa reinscrição é esse o vínculo que o torna dependente, a partir daí, de um Outro, cuja estrutura não depende dele (Lacan, 2008, p. 304).

No objeto a vige o ponto que introduz a dialética do sujeito do inconsciente. Em seus quatro apagamentos, o sujeito inapreensível pode se inscrever no campo do Outro para aí subsistir, a partir do registro do significante mais primário, marca da função do um (Lacan, 2008, p. 307). Portanto, na contingência da articulação da impossibilidade do gozo pleno, o que se enuncia em sua suplência é $\mathrm{S}_{1}$, que extrai o significante $U m$ encravado na linguagem. Esse significante não se reduz a um suporte fonemático, ele é o efeito do significado irreconhecível do gozo, sendo o que permite a ordenação da série significante da linguagem $\left(\mathrm{S}_{2}\right)$. Eles só operam articulados, pois a ordenação da série é o movimento de interrogação e de coletivização possível de $\mathrm{S}_{1}$ : "Não é isso - aí está o grito por onde se distingue o gozo obtido do gozo esperado" (Lacan, 1982, p. 152). S é interpelado pelo $\mathrm{S}_{2}$, esse saber sempre limitado ao gozo insuficiente que constitui o falante, ao elucubrar sobre $S_{1}$, na procura da verdade, da lei que regra o gozo, sempre mal dita. $\mathrm{S}_{2}$ é saber inconsciente que se deposita como sedimento que se produz em cada um (Lacan, 1973-1974).

\section{O não enlaçamento do Imaginário nos autismos}

Verificamos a ausência desse tempo $\mathrm{S}_{2}$ nos casos em que a condição de sujeito não encontra seus modos de articular-se ao laço social, tal como nos autismos, por não operar a extração do objeto $a$. Seus atos não chegam a equacionar uma leitura de sua relação com a alteridade. Suas manifestações não ordenam "esse tão pouco de realidade que é a nossa: essa do fantasma” (Lacan, 1973-1974).

Supõe-se, portanto, a impossibilidade presente de enodar o real da linguagem que se imiscuiu fazendo traço no corpo (por meio do qual o infans ressoa lalíngua), com o registro do imaginário que iria representá-lo (por meio do estabelecimento de comparações, similitudes ou dessemelhanças, transpondo-as para o registro discretizado da língua). É mesmo por essa via, fazendo alto ao gozo, que a clínica pode ser sustentada. Ao deslocar o que o discurso localiza como ações 
estereotipadas para situá-las num texto de seus atos, esses podem ser reescritos em outro registro (decifrados), porque tal texto promove a pontuação determinativa dos constrangimentos que ele desvela.

\section{I}

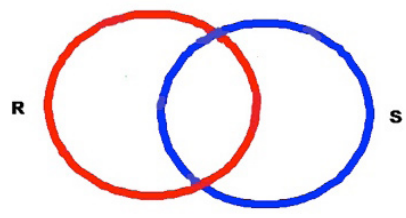

Ao emprestar elementos de seu imaginário para enlaçar as marcas que afetaram o corpo sem se encadearem, o clínico pode ensaiar apurar a lógica do ato da criança, operando enlaçamentos, substituições, deslocamentos ou nomeações que constroem uma ficção simbólica. Franqueando o estiramento da concatenação simbólica, a partir do modo singular da criança operar com o que lhe faz alteridade, o clínico pode estabelecer um distanciamento e mesmo uma mediação capaz de mobilizar a extração do objeto $a$, imprescindível na constituição do fantasma que regula a relação ao Outro.

\section{Uma provisória conclusão}

O tratamento clínico deve ser preliminar a um diagnóstico classificatório dos chamados autistas, na medida em que pode franquear acesso à constituição do imaginário, exigindo a potência dos conceitos de Construção e Ato.

Freud (1937/1975) abordou a noção de construção como uma operação necessária para a aproximação ao núcleo recalcado inconsciente. Formalizada ao final de sua obra, ele a abordara em muitas oportunidades anteriores, referidas seja à consideração do jogo entre a língua, a economia psíquica e o laço social (Freud, 1905/1975), seja à laboriosa adivinhação da cena primária a partir de uma soma de indícios (Freud, 1918/2010, p. 70), ou, ainda, àquela que permite estabelecer conexão entre tempos de diferentes estados da fantasia (Freud, 1919/2010, p. 303). 
A construção analítica extrai inferências a partir de alicerces - fragmentos de lembranças, associações e comportamentos do analisante - para erguer paredes. Reconstruindo por meio da suplementação e combinação de restos que sobreviveram, a construção é um trabalho analítico preliminar, pois implica, necessariamente, o que o analisante derrama sobre ela: está sujeita a correções, equívocos e a suas reações. A construção erguida "só é eficaz porque recupera um fragmento de experiência perdida" (Freud, 1937/1975, p. 369). Assim, a construção lúdica do analista, articulada à manifestação da criança, é a aposta para que um ato subjetivo desta possa ser situado.

A função do ato, tal como demonstrada por Lacan (1967-1968), permite-nos retirar definitivamente as manifestações de autistas do registro da estereotipia ou da ação enquanto efeito de um desencadeamento motor, da descarga ou do automatismo passivo, seja do reflexo na fuga de um estímulo intolerável, seja de uma organicidade.

$\mathrm{O}$ ato foge a essa referência. Ao contrário de uma teoria fisiológica, o estatuto do aparelho psíquico se sustenta "na defasagem, no intervalo entre o elemento aferente do arco reflexo e seu elemento eferente" (Lacan, 1967-1968).

Um ato tem sempre um correlato significante, pois implica a inscrição do sujeito em algum lugar, ultrapassando certo limiar da própria medida simbólica. Portanto, ao situar a criança como necessariamente submetida ao 
simbólico, mesmo que fora de um discurso estabelecido, podemos localizar seu ato. Isso não implica que tal ato contemple um cálculo consciente da criança. $\mathrm{O}$ ato ultrapassa o domínio do $\mathrm{Eu}$, comparecendo nos interstícios do simbólico como um saber não sabido. A ideia de falha seria um abrigo atrás do qual se dissimulam os atos propriamente ditos (Lacan, 1967-1968).

Efetivamente, lidamos com crianças que, como disse Winnicott (1978), estão freezing, congeladas na situação de fracasso. Conforme Lacan (1998e), trata-se de saber por que há algo no autista que se congela. Para tanto, em vez de tomar a manifestação da criança como automática, reflexa ou definitiva, isolada em signos estanques sem concatenação a uma lógica subjetiva mesmo que incipiente, elas devem ser localizadas em seu ato, ou seja, em um trabalho pelo qual possam sair do congelamento em que se encontram, tentando encadear significantes a esse primeiro elemento $\left(\mathrm{S}_{1}\right)$ que a condena à petrificação, na tentativa de inscrição que lhe permita extensão simbólica na qual possa comparecer entre eles. Portanto, orientamo-nos pela hipótese de que as manifestações da criança são atos estabelecidos na borda da estrutura, constituindo o texto que ordena sua tentativa de estabelecer uma realidade psíquica (Vorcaro, 1997, p. 136). Nesses atos, podemos situar passagens entre zonas erógenas que não dependem de metamorfoses naturais, mas que operam pela intervenção do que não é do campo das pulsões: a demanda do Outro (Lacan, 2005). As respostas e apelos da criança dependem incondicionalmente da demanda do Outro. Entretanto, o referente de todo movimento das pulsões é o objeto a, esse operador pivotante no engajamento pulsional do corpo, que conduz a causa metonímia do desejo numa temporalidade lógica, sempre ligada à constituição do sujeito no lugar do Outro:

o parceiro desse en que é o sujeito, sujeito de qualquer frase de pedido é, não o Outro, mas o que vem se substituir a ele na forma da causa do desejo... É enquanto substitutos do Outro que esses objetos são reclamados e se fazem causa do desejo (Lacan, 1982, p. 171).

Cabe ao clínico inventar modos de retirar dessas demandas o caráter de intrusão avassaladora para operar contornos que permitam a extração do objeto $a$, impedindo que o corpo sucumba à dispersão de um gozo caótico e franqueando o engajamento no corpo pelo significante: o sujeito "só se sustenta pela extração do objeto $a$ que, no entanto, lhe fornece seu enquadre"(Lacan, 1959/1998b, p. 560).

Para resgatar esse trabalho da criança que tenta construir uma realidade psíquica, é necessário, antes, demarcar a lógica do ciframento que lhe é possível, seus fueros sobreviventes em que vigoram leis anacrônicas (Freud, 1896/1977, p. 317-318), destacando as cifras de seus atos enigmáticos da textura com que a criança sustenta sua imparidade à alteridade. PARADOXES OF PSYCHOANALYTICAL DLAGNOSES IN AUTISMS 


\begin{abstract}
This study presents the subjective constitution as conceived by Freud and Lacan through the deployment of the Borromean knot, in the articulation of the registers of the Real, the Symbolic, and the Imaginary. The first two positions of crossing registers are described in order to present a bypothesis of the tie-up of such registers in autisms. It is concluded by pointing bases of clinical operations for the treatment of autism with the psychoanalytical concepts of construction and act.
\end{abstract}

Index terms: autism; psychoanalysis; Borromean knot.

\title{
PARADOJAS DEL DLAGNÓSTICO PSICOANALÍTICO EN LOS AUTISMOS
}

\section{RESUMen}

En este texto se presenta la constitución subjetiva tal como concebida por Freudy Lacan, mediante el desdoblamiento del nudo borromeo, en el entramado de los registros real, simbólico e imaginario. Las dos primeras posiciones de cruzamiento de los registros son detalladas para presentar una hipótesis de paralización de tales registros en los autismos. Apuntando bases de las operaciones clínicas del tratamiento del autismo se concluye con los conceptos de construcción y de acto en psicoanálisis.

Palabras clave: autismo; psicoanálisis; nudo borromeo.

\section{REFERÊNCIAS}

Freud, S. (1975). Os chistes e sua relação com o inconsciente. In S. Freud, Edição standard brasileira das obras psicológicas completas de Sigmund Freud (J. Salomão, trad., Vol. 8, 11-219). Rio de Janeiro, RJ: Imago. (Trabalho original publicado em 1905)

Freud, S. (1975). Construções em análise. In S. Freud, Edição standard brasileira das obras psicológicas completas de Sigmund Freud (J. Salomão, trad., Vol. 23, 289-304). Rio de Janeiro, RJ: Imago. (Trabalho original publicado em 1937)

Freud, S. (1977). Projeto para uma psicologia científica. In S. Freud, Edição standard brasileira das obras psicológicas completas de Sigmund Freud (J. Salomão, trad., Vol. 1, 381-393). Rio de Janeiro, RJ: Imago. (Trabalho original publicado em 1895)

Freud, S. (1977). Carta 52. In S. Freud, Edição standard brasileira das obras psicológicas completas de Sigmund Freud (J. Salomão, trad., Vol. 1, pp.317-324). Rio de Janeiro, RJ: Imago. (Trabalho original publicado em 1896)

Freud, S. (1988). A negativa. Letra Freudiana, VIII (5). Rio de Janeiro, RJ: TaurusTimbre. (Trabalho original publicado em 1925)

Freud, S. (1992). Inibiçâo, sintoma e angústia, vol. XX. Buenos Aires: Amorrortu. (Trabalho original publicado em 1926)

Freud, S. (2006). Além do princípio de prazer. In S. Freud, Escritos sobre a Psicologia do inconsciente (Vol. 2, pp.123-198). Rio de Janeiro, RJ: Imago. (Trabalho original publicado em 1920)

Freud, S. (2007). O Eu e o isso. In S. Freud, Escritos sobre a psicologia do inconsciente. (Vol. 3, pp.13-92). Rio de Janeiro, RJ: Imago. (Trabalho original publicado em 1923) 
Freud, S. (2010). História de uma neurose infantil (o homem dos lobos). In S. Freud, Sigmund Freud: obras completas (Vol. 14, pp. 9-119). São Paulo, SP: Companhia das Letras. (Trabalho original publicado em 1918)

Freud, S. (2010). Bate-se numa criança. In S. Freud, Sigmund Freud: obras completas (Vol. 14, pp. 220-246). São Paulo, SP: Companhia das Letras. (Trabalho original publicado em 1919)

Freud, S. (2011). O Eu e o id. In S. Freud, Sigmund Freud: obras completas (Vol. 16, pp. 9-64). São Paulo, SP: Companhia das Letras. (Trabalho original publicado em 1923)

Freud, S. (2011). Alguns complementos à interpretação dos sonhos. In S. Freud, Sigmund Freud: obras completas (Vol. 16, pp. 288-302). São Paulo, SP: Companhia das Letras. (Trabalho original publicado em 1925)

Freud, S. (2013). Psicologia das massas e análise do eu. Porto Alegre, RS: L\&PM. (Trabalho original publicado em 1921)

Freud, S. (2014). O homem Moisés e a religião monoteista. Porto Alegre, RS: L\&PM. (Trabalho original publicado em 1939)

Lacan, J. (1961-1962). Seminário 9: a identificação. Não publicado.

Lacan, J. (1966-1967). Seminário 14: a lógica da fantasia. Não publicado.

Lacan, J. (1967-1968). Seminário 15: o ato analitico. Não publicado.

Lacan, J. (1973-1974). Seminário 21: les non dupes errent. Não publicado.

Lacan, J. (1974-1975). Seminário 22: RSI. Não publicado.

Lacan, J. (1982). O seminário, livro 20: mais ainda, 1972-1973. Rio de Janeiro, RJ: Jorge Zahar.

Lacan, J. (1988a). O seminário, livro 7: a ética da psicanálise, 1959-1960. Rio de Janeiro, RJ: Jorge Zahar.

Lacan, J. (1988b). O seminário, livro 11: os quatro conceitos fundamentais da psicanálise, 1964. Rio de Janeiro, RJ: Jorge Zahar.

Lacan, J. (1992a). O seminário, livro 8: a transferência, 1960-1961. Rio de Janeiro Jorge Zahar.

Lacan, J. (1992b). O seminário, livro 17: o avesso da psicanálise, 1969-1970. Rio de Janeiro, RJ: Jorge Zahar.

Lacan, J. (1998a) O seminário, livro 5: as formaçōes do inconsciente, 1957-1958. Rio de Janeiro, RJ: Jorge Zahar.

Lacan, J. (1998b). De uma questáo preliminar a todo tratamento possível da psicose. In J. Lacan, Escritos (pp.537-590). Rio de Janeiro, RJ: Jorge Zahar. (Trabalho original publicado em 1959)

Lacan, J. (1998c). Posição do inconsciente no congresso de Bonneval. In J. Lacan, Escritos (843-864). Rio de Janeiro, RJ: Jorge Zahar. (Trabalho original publicado em 1960, retomado em 1964)

Lacan, J. (1998d). Observação sobre o relatório de Daniel Lagache. In J. Lacan, Escritos (653-691). Rio de Janeiro, RJ: Jorge Zahar. (Trabalho original publicado em 1966)

Lacan, J. (1998e). Conferência em Genebra sobre o sintoma (04/10/1975). Opção lacaniana, 23, 06-16.

Lacan, J. (2003). O aturdito. In J. Lacan, Outros escritos (pp.448-497). Rio de Janeiro, RJ: Jorge Zahar. (Trabalho original publicado em 1973) 
Lacan, J. (2005). O seminário, livro 10: a angústia, 1962-1963. Rio de Janeiro, RJ: Jorge Zahar.

Lacan, J. (2008). O seminário, livro 16: de um Outro ao outro, 1968-1969. Rio de Janeiro, RJ: Jorge Zahar.

Lacan, J. (2009). O seminário, livro 18: de um discurso que não fosse semblante, 19701971. Rio de Janeiro, RJ: Jorge Zahar.

Lacan, J. (2013). Le seminaire, livre 6: le désir e son interpretation, 1958-1959. Paris: La Martinière.

Masson, J. (1986). A correspondência completa de Sigmund Freud para Wilhelm Fliess -1887-1904. Rio de Janeiro, RJ: Imago.

Milner, J.-C. (2006). Os nomes indistintos. Rio de Janeiro, RJ: Cia de Freud.

Vorcaro, A. (1997). A criança na clínica psicanalítica. Rio de Janeiro, RJ: Cia de Freud.

Vorcaro, A. (2009). Topologia da formação do inconsciente: o efeito sujeito. Estudos Lacanianos, II (3), 45-62.

Winnicott, D. W. (1978). Aspectos clínicos e metapsicológicos da regressão dentro do setting psicanalítico. In D. W. Winnicott, Textos selecionados: da pediatria à psicanálise (1954-1955) (pp. 374-392). Rio de Janeiro, RJ: Francisco Alves.

\section{NOTA}

1. A constatação do fracasso dessa promessa, na relação sexual exigirá, na adolescência, a nominação de um quarto elo, que comporá então o nó borromeano como nominação (Real, Simbólica ou Imaginária). Prevalecerão, então, como modalidades de resposta subjetiva, a inibição, sintoma ou angústia. Assim, o nó borromeano mostra não ser normativo quanto à relação $R, S$, I, pois estas só incidem orientadas pela nominação da versão paterna do gozo.

angelavorcaro@uol.com.br

Rua Paul Bouthilier, 353

30315-010 - Belo Horizonte - MG - Brasil.

Recebido em setembro/2016.

Aceito em novembro/2016. 